\title{
Supplementary 1: Materials
}

Quan-Hoang Vuong ${ }^{1,2, *}$, Manh-Toan Ho ${ }^{1,3}$, Minh-Hoang Nguyen ${ }^{1,3}$, Thanh-Hang Pham ${ }^{4,5}$, HoangAnh Ho ${ }^{1}$, Thu-Trang Vuong ${ }^{6}$, Viet-Phuong La ${ }^{1,3}$

${ }^{1}$ Centre for Interdisciplinary Social Research, Phenikaa University, Yen Nghia Ward, Ha Dong District, Hanoi 100803, Vietnam

2 Centre Emile Bernheim, Université Libre de Bruxelles, 1050 Brussels, Belgium

3 A.I. for Social Data Lab, Vuong \& Associates, 3/161 Thinh Quang, Dong Da District, Hanoi, 100000, Viet Nam

${ }^{4}$ Faculty of Management and Tourism, Hanoi University, Km9, Nguyen Trai Road, Thanh Xuan, Hanoi 100803, Vietnam

${ }^{5}$ School of Business, RMIT Vietnam University, Hanoi, 100000, Viet Nam

${ }^{6}$ Sciences Po Paris, 27 Rue Saint-Guillaume, 75007 Paris, France

*Contact: Quan-Hoang Vuong (qvuong@ulb.ac.be); Manh-Toan Ho (toan.homanh@phenikaauni.edu.vn)

1. Aim

In this supplementary file, we present the materials employed in all the analyses and their detailed descriptions. Our materials consist of two datasets:

- Dataset [1]: 584 observations collected from $15^{\text {th }}$ May to $28^{\text {th }}$ May 2020

- Dataset [2]: 503 observations collected from $15^{\text {th }}$ May to $25^{\text {th }}$ May 2020

\section{Survey collection}

On $15^{\text {th }}$ May 2020, we started the survey collection by posting questionnaires on multiple communities of Animal Crossing: New Horizons (ACNH) players on Facebook, Reddit, and Discord servers. Before posting, we had contacted the admin and moderator team of each community for validation. During the validation process, the purpose and contents of the questionnaires were clearly explained to comply with the community's rules and standards. After being approved, the questionnaire was published with the validation of the admin/moderator team and a clear explanation of the study's purpose. The respondents would be asked to read and agree to a consent form before doing the questionnaire. Also, we provided $\$ 5$ Amazon gift cards to the first hundred respondents and $2 \$$ Amazon gift cards to the next two hundred respondents as thank-you presents. Table S1_1 summarizes the information of Animal Crossing communities in which the data collection was conducted.

Table S1_1. Animal Crossing communities across platforms where we conducted the data collection.

\begin{tabular}{|c|c|c|c|}
\hline Order & Community & Platform & Starting date \\
\hline 1 & Cộng đồng Nintendo Switch Việt Nam - SwitchVN Community & Facebook & $\begin{array}{c}15^{\text {th }} \text { May } \\
2020\end{array}$ \\
\hline 2 & $\begin{array}{c}\text { CLB địa chủ Animal Crossing New Horizons - Nintendo Switch Việt } \\
\text { Nam }\end{array}$ & Facebook & $\begin{array}{c}15^{\text {th }} \text { May } \\
2020\end{array}$ \\
\hline 3 & Animal Crossing: New Horizons Over 25's Club & Facebook & $\begin{array}{c}19^{\text {th }} \text { May } \\
2020\end{array}$ \\
\hline
\end{tabular}




\begin{tabular}{|c|c|c|c|}
\hline 4 & r/Animal Crossing & Reddit & $\begin{array}{c}19^{\text {th }} \text { May } \\
2020\end{array}$ \\
\hline 5 & Animal Crossing Community (UK) & Facebook & $\begin{array}{c}24^{\text {th }} \text { May } \\
2020\end{array}$ \\
\hline 6 & Animal Crossing: New Horizons Philippines & Facebook & $\begin{array}{c}25^{\text {th }} \text { May } \\
2020\end{array}$ \\
\hline 7 & Animal Crossing: New Horizons Myanmar MM & Facebook & $\begin{array}{c}25^{\text {th }} \text { May } \\
2020\end{array}$ \\
\hline 8 & Animal Crossing: Arts and Codes (ACAC) & Facebook & $\begin{array}{c}25^{\text {th }} \text { May } \\
2020\end{array}$ \\
\hline 9 & Animal Crossing: New Horizons & Discord & $\begin{array}{c}24^{\text {th }} \text { May } \\
2020\end{array}$ \\
\hline
\end{tabular}

\section{Questionnaire design}

The questionnaire was designed to examine four primary aspects of $\mathrm{ACNH}$ players: 1) socio-demographic information, 2) game playing experience, 3) in-game behaviors, and 4) environmental perceptions.

The socio-demographic information consists of eight factors: nationality, biological sex, educational level, owning a pet/garden or not, age, ethnicity, marital status, and employment status. These factors are coded from A1 to A8, respectively. The experience of game-playing is measured by a set of 39 questions. The details are not described here due to their irrelevance.

In-game behaviors of $\mathrm{ACNH}$ players are examined through a set of 30 questions. The questions are self-designed to observe how players deal with environmental factors in ACNH (fish, bug, flower, tree, mystery island, and "terraforming"- the ability to modify the land).

To explore environmental perceptions of game players, we employ 15 questions of the New Environmental Paradigm (NEP) scale (Dunlap, Van Liere, Mertig, \& Jones, 2000). This is seemingly the most well-known scale to measure environmental perceptions, which has been used in multiple disciplines and scenarios (Attari, DeKay, Davidson, \& De Bruin, 2010; Budescu, Por, Broomell, \& Smithson, 2014; de Bruin \& Bostrom, 2013; Schwartz, Loewenstein, \& Agüero-Gaete, 2020). The reporting of the results and limitations strictly follows the principle of Vuong (2020).

\section{Data description}

\subsection{Raw data description}

\begin{tabular}{|c|c|c|c|}
\hline \multicolumn{2}{|c|}{ Dataset [1]: 584 observations } & \multicolumn{2}{|c|}{ Dataset [2]: 503 observation } \\
\hline \multicolumn{4}{|c|}{ Geographical regions } \\
\hline Region & Count & Region & Count \\
\hline Asia & 161 & Asia & 119 \\
\hline EU & 86 & $\mathrm{EU}$ & 79 \\
\hline Other & 16 & Other & 12 \\
\hline US/Canada & 321 & US/Canada & 293 \\
\hline
\end{tabular}




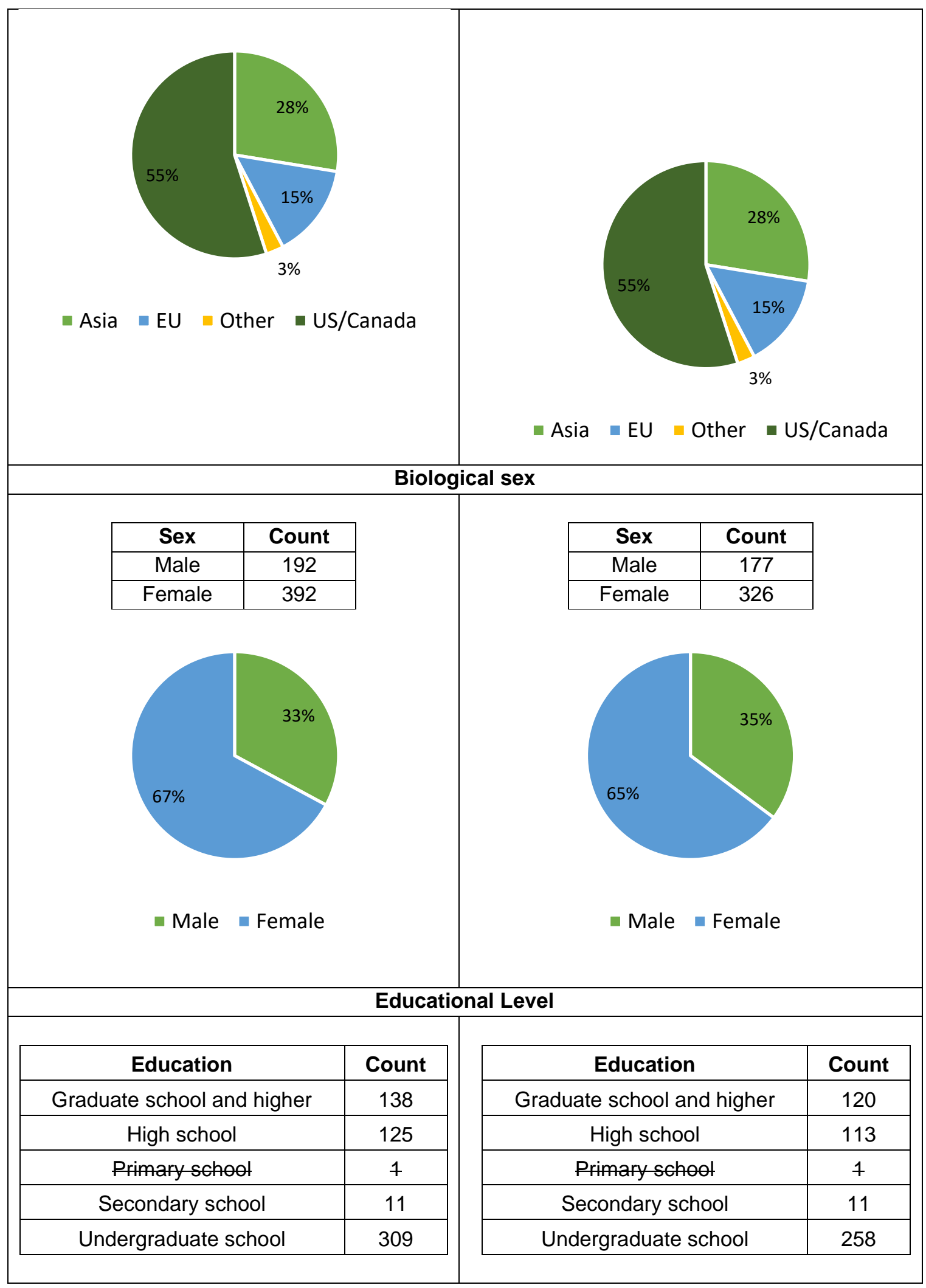




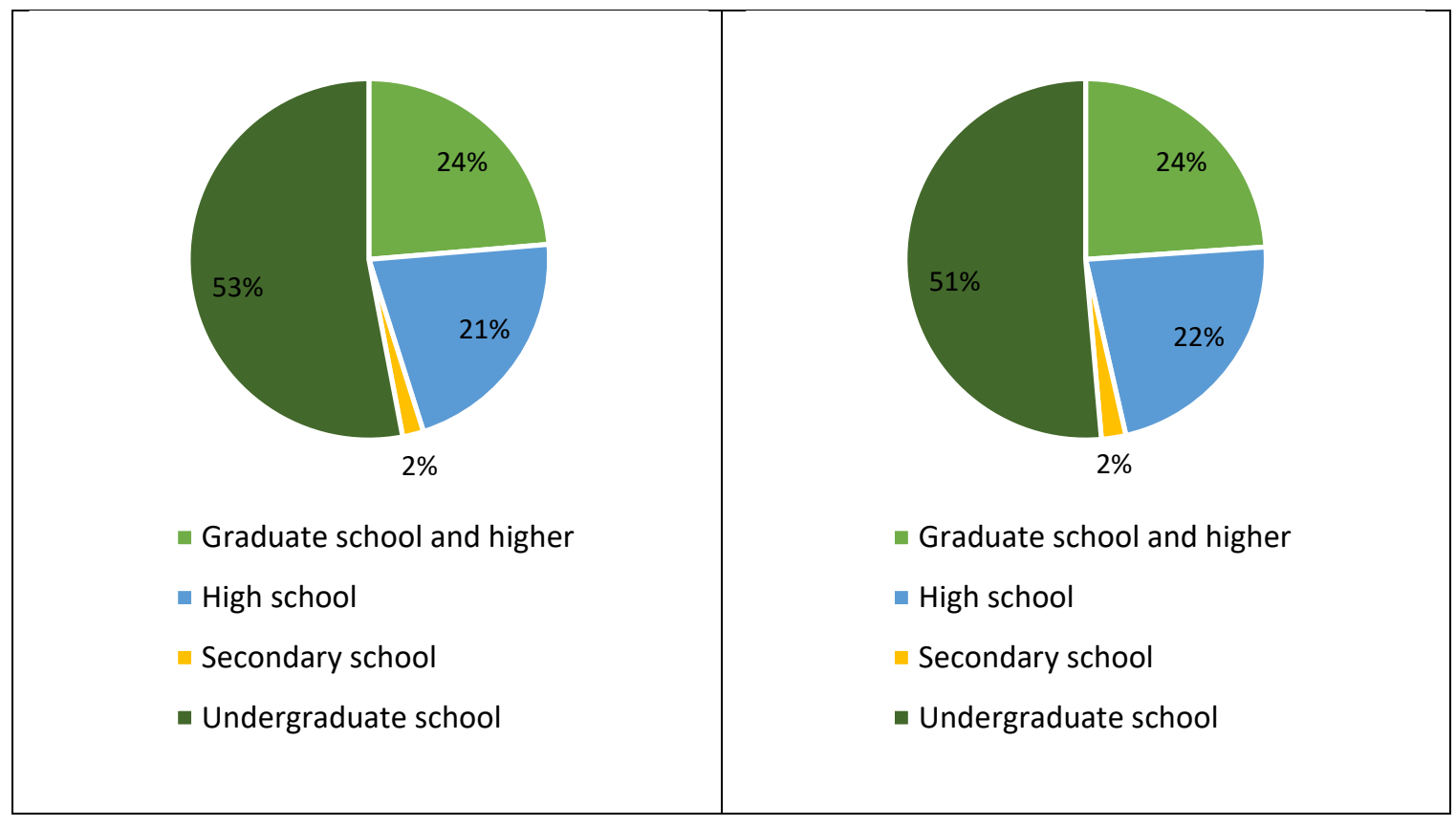

4.2. Filtered data for estimating the probability distribution of environmental perceptions

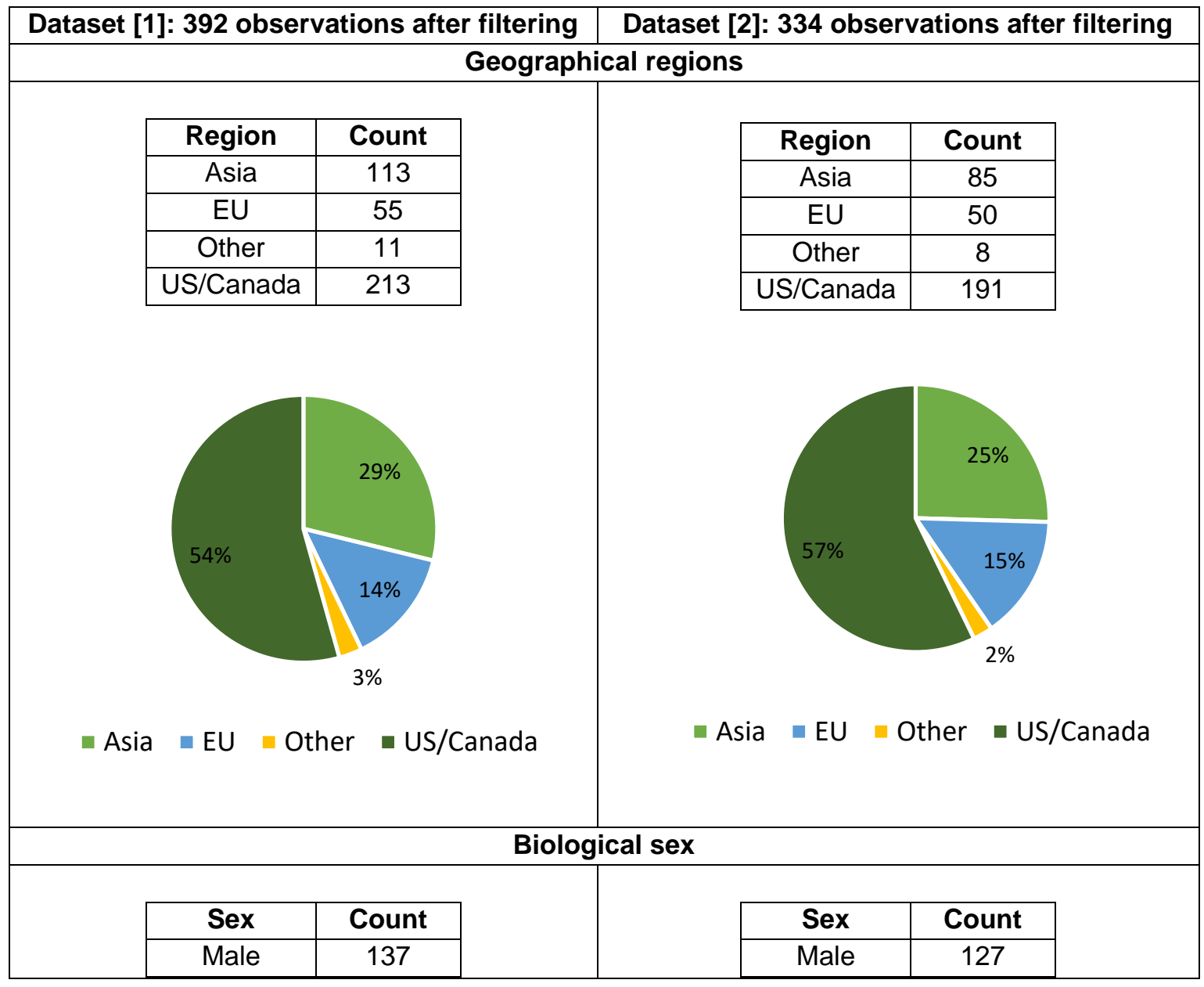




\begin{tabular}{|c|c|c|c|c|c|}
\hline Female & 255 & & Female & 207 & \\
\hline \multicolumn{3}{|c|}{ Male $\quad$ Female } & \multicolumn{3}{|c|}{ " Male $\quad$ Female } \\
\hline \multicolumn{6}{|c|}{ Educational Level } \\
\hline \multicolumn{2}{|l|}{ Education } & Count & \multicolumn{2}{|l|}{ Education } & Count \\
\hline \multicolumn{2}{|c|}{ Graduate school and higher } & 93 & \multicolumn{2}{|c|}{ Graduate school and higher } & 83 \\
\hline \multicolumn{2}{|l|}{ High school } & 77 & \multicolumn{2}{|c|}{ High school } & 68 \\
\hline \multicolumn{2}{|c|}{ Secondary school } & 10 & \multicolumn{2}{|c|}{ Secondary school } & 10 \\
\hline \multicolumn{2}{|c|}{ Undergraduate school } & 212 & \multicolumn{2}{|c|}{ Undergraduate school } & 173 \\
\hline \multicolumn{3}{|c|}{$\begin{array}{l}\text { - Graduate school and higher } \\
\text { - High school } \\
\text { Secondary school } \\
\text { - Undergraduate school }\end{array}$} & \multicolumn{3}{|c|}{$\begin{array}{l}\text { - Graduate school and higher } \\
\text { - High school } \\
\text { - Secondary school } \\
\text { - Undergraduate school }\end{array}$} \\
\hline \multicolumn{6}{|c|}{ Environmental perceptions (C2) } \\
\hline Agreement & Count & & Agreement & Count & \\
\hline Agree & 183 & & Agree & 161 & \\
\hline Disagree & 209 & & Disagree & 173 & \\
\hline
\end{tabular}



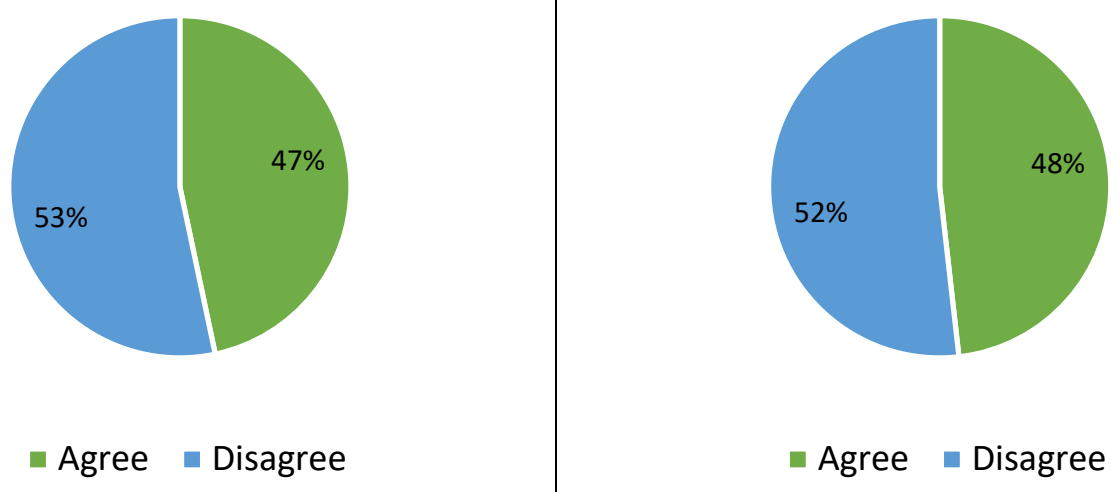

- Agree $\square$ Disagree

4.3. Filtered data for estimating the probability distribution of in-game behaviors

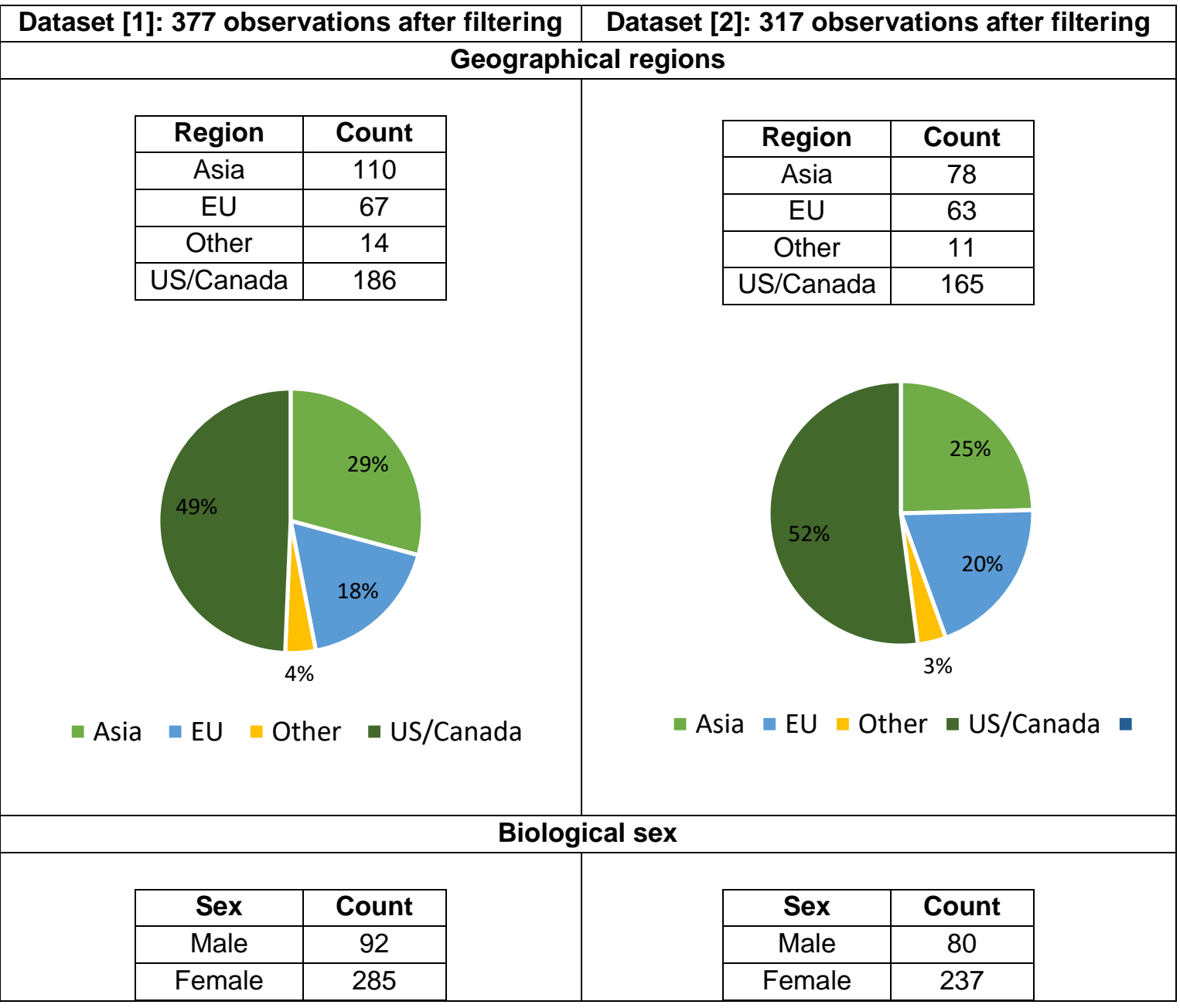




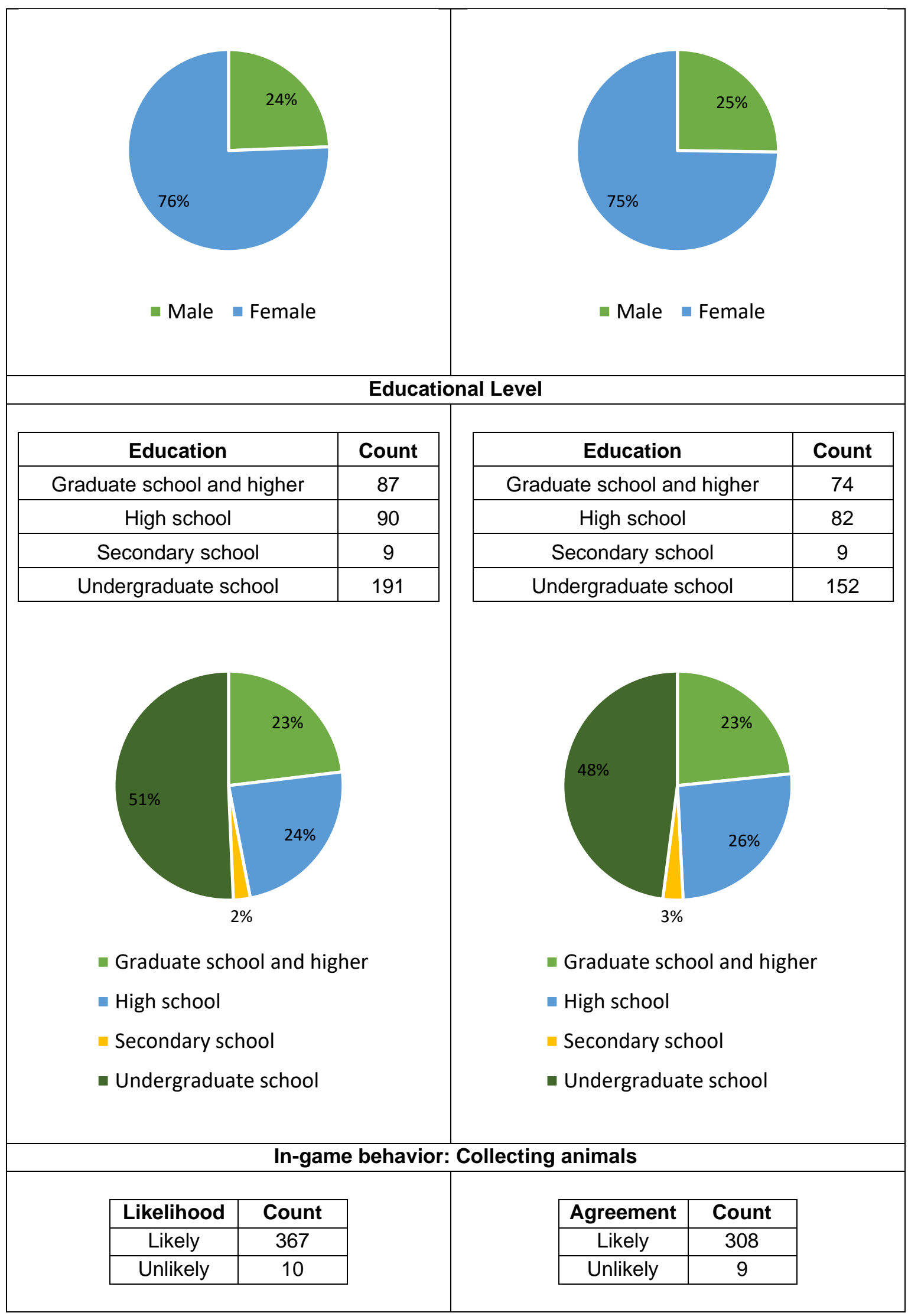




\begin{tabular}{|c|c|c|c|}
\hline & & \\
\hline
\end{tabular}

4.4. Filtered data for estimating the correlation between environmental perceptions and in-game behaviors

Dataset [1]: 256 observations after filtering $\quad$ Dataset [2]: 210 observations after filtering Biological sex

\begin{tabular}{|c|c|}
\hline Sex & Count \\
\hline Male & 68 \\
\hline Female & 188 \\
\hline
\end{tabular}

\begin{tabular}{|c|c|}
\hline Sex & Count \\
\hline Male & 60 \\
\hline Female & 150 \\
\hline
\end{tabular}




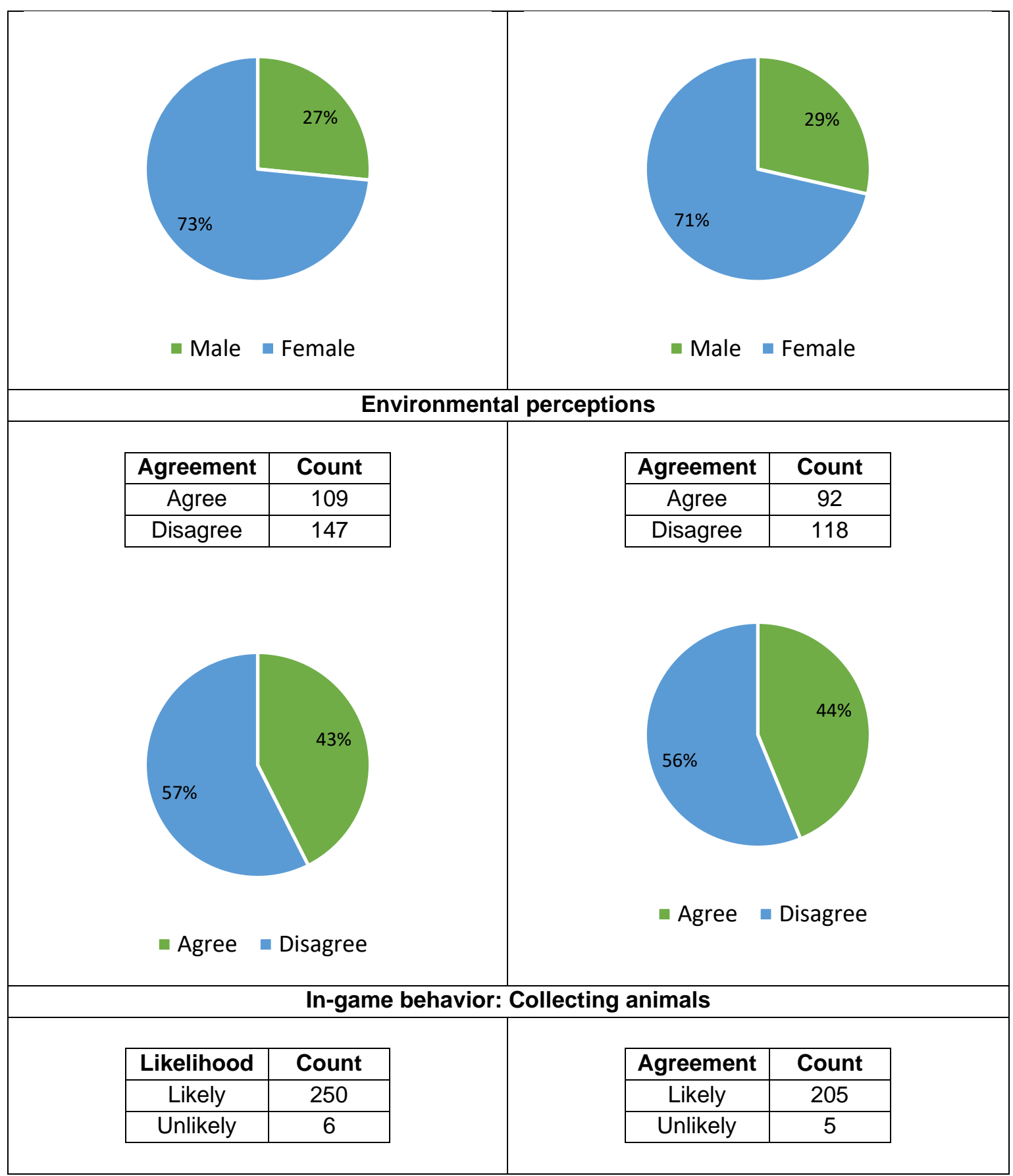




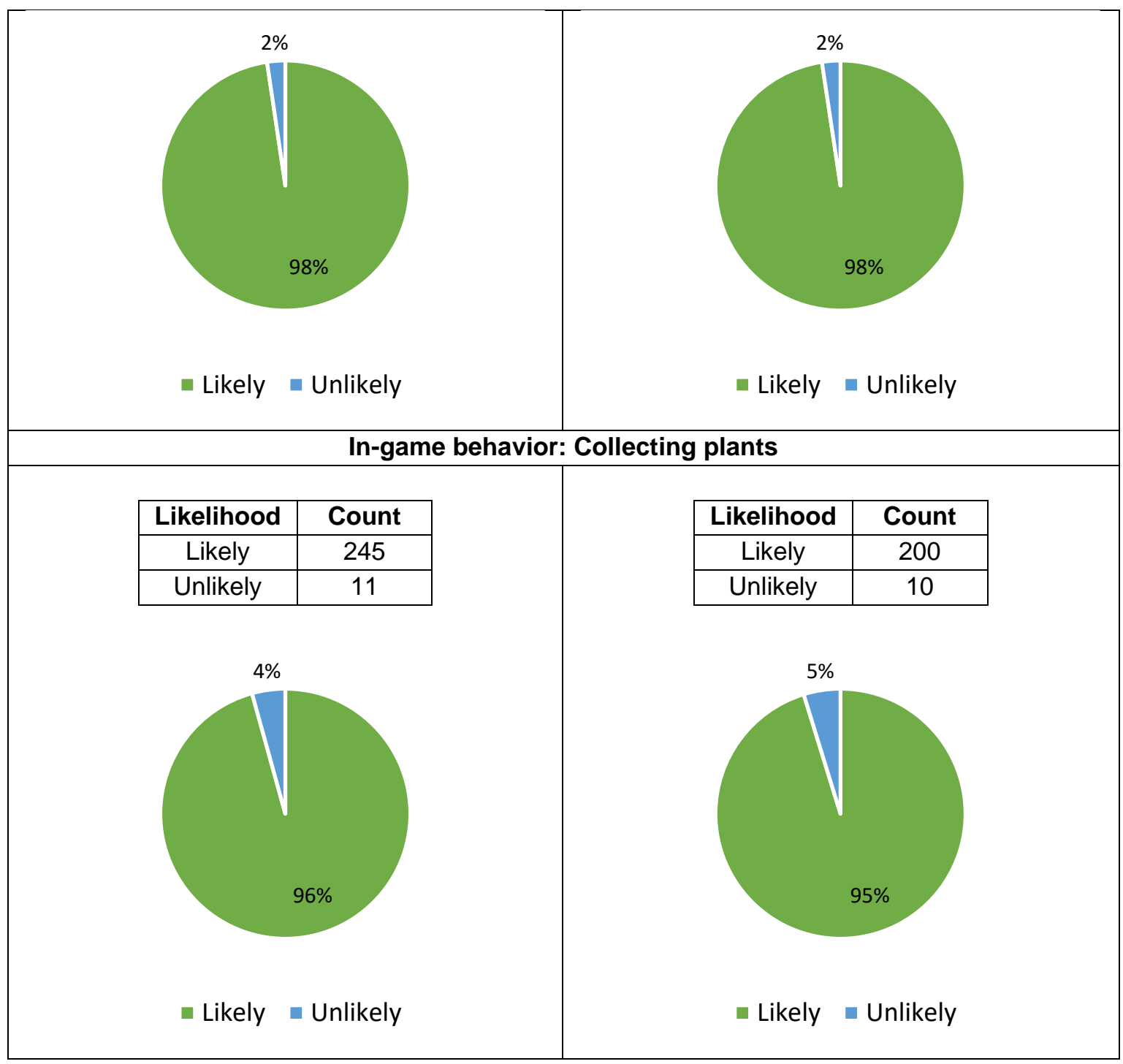

\section{References}

Attari, S. Z., DeKay, M. L., Davidson, C. I., \& De Bruin, W. B. (2010). Public perceptions of energy consumption and savings. Proceedings of the National Academy of Sciences, 107(37), 16054-16059.

Budescu, D. V., Por, H.-H., Broomell, S. B., \& Smithson, M. (2014). The interpretation of IPCC probabilistic statements around the world. Nature Climate Change, 4(6), 508-512.

de Bruin, W. B., \& Bostrom, A. (2013). Assessing what to address in science communication. Proceedings of the National Academy of Sciences, 110 (Supplement 3), 14062-14068.

Dunlap, R. E., Van Liere, K. D., Mertig, A. G., \& Jones, R. E. (2000). New trends in measuring environmental attitudes: measuring endorsement of the new ecological paradigm: a revised NEP scale. Journal of social issues, 56(3), 425-442. 
Schwartz, D., Loewenstein, G., \& Agüero-Gaete, L. (2020). Encouraging proenvironmental behaviour through green identity labelling. Nature Sustainability, 1-7.

Vuong, Q. H. (2020). Reform retractions to make them more transparent. Nature, 582(7811), 149. doi:10.1038/d41586-020-01694-X 